(C) Dereito Vol.27, $\mathrm{n}^{0}: 61-84$ (Xullo-Decembro, 2018) • ISSN 1132-9947

\title{
IMPLICACIONES DE LAS RESIDENCIAS GERIÁTRICAS EN LA TRIBUTACIÓN DE LAS ADQUISICIONES MORTIS CAUSA
}

The incidence of residing in a geriatric residence in the taxation of mortis causa acquisitions

DOI: http://dx.doi.org/10.15304/dereito.27.2.5084

IRENE ROVIRA FERRER

Profesora Agregada de Derecho Financiero y Tributario

Universitat Oberta de Catalunya

iroviraf@uoc.edu

\section{Resumen}

El objetivo principal del presente trabajo es el análisis de los diferentes aspectos de la tributación de las adquisiciones mortis causa en los que puede incidir el hecho de habitar en una residencia geriátrica, ya sea por parte del causante o del adquirente. En concreto, dentro del ámbito del ISD, se determinará su implicación en la sujeción al Impuesto por parte del adquirente, en su cesión, en la reducción de la base imponible por la transmisión de la vivienda habitual del causante, en el cálculo del ajuar doméstico y en la bonificación de la cuota por la residencia en Ceuta o Melilla, acabando con el análisis de la bonificación prevista en el IIVTNU en relación con la adquisición de la vivienda habitual del causante que prevén algunos Ayuntamientos.

Palabras clave: Impuesto sobre Sucesiones y Donaciones, Incremento de Valor de los Terrenos de Naturaleza Urbana, vivienda habitual, residencia geriátrica, adquisiciones mortis causa.

\section{Abstract}

The main scope of this study is the analysis of the incidence of residing in a geriatric residence in the taxation of mortis causa acquisitions. Specifically, within the scope of the Inheritance and Gift Tax, this incidence will be determined in the subjection to the Tax of the purchasers, in the transfer of the Tax, in the reduction of the tax base for the transmission of the main residence of the deceased, in the calculation of the household items and in the reduction of tax liability due to the residence in Ceuta or Melilla. Finally, we will also analyse the incidence in the optional reduction in the amount of the Tax on the Increase in Value of Urban Land due to the transmission of the main residence of the deceased.

Keywords: Inheritance and Gift Tax, Tax on the Increase in Value of Urban Land, main residence, geriatric residence, mortis causa acquisitions.

Recibido: 04/09/2018. Aceptado: 05/12/2018. 


\section{SUMARIO}

1. INTRODUCCIÓN.; -2. IMPLICACIÓN EN LA SUJECIÓN AL IMPUESTO DEL ADQUIRENTE.; -3. IMPLICACIÓN EN LA CESIÓN DEL IMPUESTO.; -4. IMPLICACIÓN EN LA REDUCCIÓN DE LA BASE IMPONIBLE POR LA TRANSMISIÓN DE LA VIVIENDA HABITUAL DEL CAUSANTE.; -5. IMPLICACIÓN EN EL CÁLCULO DEL AJUAR DOMÉSTICO.; -6. IMPLICACIÓN EN LA BONIFICACIÓN DE LA CUOTA POR LA RESIDENCIA EN CEUTA O MELILLA.; -7. IMPLICACIÓN EN LA POTESTATIVA BONIFICACIÓN DE LA CUOTA ÍNTEGRA DEL IIVTNU DERIVADA DE LA ADQUISICIÓN MORTIS CAUSA DE LA VIVIENDA HABITUAL DEL CAUSANTE.; -8. CONCLUSIONES.; -9. BIBLIOGRAFÍA.

\section{INTRODUCCIÓN}

Cada vez es más habitual que, a la hora de determinar la tributación de las adquisiciones mortis causa, el causante se encontrara habitando en una residencia geriátrica, lo mismo que puede ocurrir respecto del propio adquirente.

Y este hecho, ciertamente, no resulta indiferente a la hora de aplicar el Impuesto sobre Sucesiones y Donaciones (ISD), tanto a la hora de determinar la sujeción al mismo por parte del adquirente, de concretar su cesión o de valorar la reducción de la base imponible por la transmisión de la vivienda habitual del causante, como a la hora de calcular el ajuar doméstico o de valorar la procedencia de la bonificación de la cuota por la residencia en Ceuta o Melilla.

Sin embargo, la determinación de la incidencia de las residencias geriátricas en tales aspectos no siempre resulta sencilla ni exenta de polémica, punto en el que debe añadirse la complejidad implícita en el Impuesto por cuanto no sólo el Estado tiene competencias normativas al respecto.

Así, y aunque sea de titularidad estatal (regulado por la Ley 29/1987, de 18 de diciembre, del Impuesto sobre Sucesiones y Donaciones -LISDy el Reglamento del Impuesto sobre Sucesiones y Donaciones -RISD-, aprobado por el Real Decreto 1629/1991, de 8 de noviembre), tanto las Diputaciones forales de los territorios históricos del País Vasco como la Comunidad Foral de Navarra tienen reconocidas, entre otras, competencias normativas sobre el mismo (ya que, de conformidad con el art. 25 del Concierto económico con el País Vasco -aprobado por la Ley 12/2002, de 23 de mayo- y el art. 31 del Convenio económico con Navarra -aprobado por la Ley 28/1990, de 26 de diciembre-, tiene la consideración de tributo concertado de normativa autónoma), del mismo modo que las tienen el resto de Comunidades Autónomas (CCAA) de régimen común en tanto que se trata de un tributo cedido (de acuerdo con el art.11.d) de la Ley Orgánica 8/1980, de 22 de septiembre, de Financiación de las Comunidades Autónomas -LOFCA- y desarrolla la Ley 22/2009, de 18 de diciembre, por la que se regula el sistema de financiación de las Comunidades Autónomas de régimen común y Ciudades con Estatuto de Autonomía y se modifican determinadas normas tributarias). 
No obstante, mientras que los territorios forales tienen plena capacidad para configurar los elementos principales del tributo ${ }^{1}$, en el resto de CCAA se encuentra limitada a los aspectos que precisa el art. 48 de la Ley 22/2009, si bien, en ambos casos, será de aplicación la regulación que se desarrolle cuando resulte cedido el rendimiento del Impuesto conforme a los pertinentes puntos de conexión ${ }^{2}$ (lo que también comportará la cesión de competencias para su aplicación y revisión).

Sin embargo, la completa valoración de la incidencia de las residencias geriátricas en la tributación de las adquisiciones mortis causa no sólo se limita al ámbito del ISD, sino que también requiere analizar la bonificación que pueden establecer las entidades locales a la cuota íntegra del Impuesto sobre el Incremento de Valor de los Terrenos de Naturaleza Urbana (IIVTNU) conforme el art. 108.4 del Texto Refundido de la Ley Reguladora de las Haciendas Locales (TRLRHL), aprobado por el Real Decreto Legislativo 2/2004, de 5 de marzo.

$Y$ es que, a pesar de que el mencionado precepto contemple la posibilidad de establecer tal bonificación para las transmisiones de terrenos, y la transmisión o constitución de derechos reales de goce limitativos del dominio, realizadas a título lucrativo por causa de muerte, algunos Ayuntamientos la han previsto para el caso de que la adquisición lucrativa recibida sea la vivienda habitual del causante, por lo que también en este punto deberá acudirse a la pertinente normativa municipal para determinar cómo deberá procederse en los supuestos aquí estudiados.

Así pues, el análisis general de la incidencia de las residencias geriátricas en la tributación de las adquisiciones mortis causa constituye el objeto del presente trabajo, procurando determinar la aplicación normativa de los aspectos en los que puedan influir, poniendo de manifiesto las cuestiones problemáticas que se plantean y aportando algunas propuestas de mejora que pueden resultar de interés.

\section{IMPLICACIÓN EN LA SUJECIÓN AL IMPUESTO DEL ADQUIRENTE}

El primer aspecto en el que las residencias geriátricas pueden conllevar importantes consecuencias en la tributación de las adquisiciones mortis causa es en relación con la sujeción al ISD por parte del adquirente, concretamente en el caso de que el mismo se encuentre habitando en una.

Así, procede recordar que los contribuyentes pueden estar sujetos al ISD por obligación personal o real de contribuir, exigiéndoseles el

\footnotetext{
${ }^{1}$ De todos modos, y aunque su capacidad se entiende completa por regla general, no es ilimitada, sino que se encuentra supeditada a determinados principios y limitaciones como son, además de los establecidos por la Constitución (CE) con base en su supremacía, los previstos en los arts. 2 a 4 del Concierto económico con el País Vasco y 2 del Convenio económico con Navarra. Además, no hay que olvidar los límites derivados de los tratados o convenios internacionales suscritos por el Estado, así como los directamente procedentes de la Unión Europea (UE).

2 Sin perjuicio de la aplicación de la normativa autonómica que también resultará procedente a pesar de que no resulte cedido de conformidad con la Disposición adicional segunda de la LISD.
} 
Impuesto, en el primer caso, con independencia de dónde se encuentren situados los bienes o derechos que integren el incremento de patrimonio gravado, pero quedando únicamente vinculados, en el segundo, por la adquisición de bienes y derechos, cualquiera que sea su naturaleza, que estuvieran situados, pudieran ejercitarse o hubieran de cumplirse en territorio español (así como por la percepción de cantidades derivadas de contratos sobre la vida cuando el contrato hubiera sido firmado con las aseguradoras españolas o que se hubiera formalizado en España con aseguradoras extranjeras que operen en el país).

De este modo, conforme al art. 6 de la LISD, estarán sujetos al Impuesto por obligación personal de contribuir aquellos adquirentes que tengan su residencia habitual en España, lo que, excepto en el caso de las personas de nacionalidad española que tengan la residencia habitual en otro país por su condición de representantes y funcionarios del Estado español en el extranjero (que estarán siempre vinculados por obligación personal), se determinará conforme a las normas del Impuesto sobre la Renta de las Personas Físicas (IRPF).

$Y$ en este punto, señala el art. 9 de la Ley 35/2006, de 28 de noviembre, del Impuesto sobre la Renta de las Personas Físicas y de modificación parcial de las Leyes de los Impuestos sobre Sociedades, sobre la Renta de no Residentes y sobre el Patrimonio (LIRPF), que, entre otros criterios, se considerará que tienen la residencia habitual en España aquellos contribuyentes que permanezcan más de 183 días, durante el año natural, en territorio español, por lo que, si un adquirente de una transmisión mortis causa se encontrara viviendo en una residencia geriátrica española de forma efectiva en la que haya permanecido la mayor parte del tiempo señalado, tributará en el ISD por obligación personal.

\section{IMPLICACIÓN EN LA CESIÓN DEL IMPUESTO}

El siguiente aspecto en el que tendrá relevancia la permanencia en una residencia geriátrica será en relación con la cesión del ISD, es decir, a la hora de determinar si corresponderá atribuir el pertinente rendimiento y demás competencias cedidas a una CCAA de régimen común o a un territorio foral.

Así, en el caso del gravamen sobre las adquisiciones mortis causa y las cantidades percibidas por los beneficiarios de seguros sobre la vida, coinciden el art. 32 de la Ley 22/2009, el art. 25 del Concierto económico con el País Vasco y el art. 31 del Convenio económico con Navarra al señalar que se cederá el rendimiento del ISD a la pertinente CCAA o territorio foral si el causante tenía en su territorio la residencia habitual a la fecha del devengo, aunque, en el caso de las CCAA de régimen común, se limita a que los sujetos pasivos del tributo sean residentes en España.

No obstante, mientras que en el caso de Navarra y País Vasco se determinará que el causante residía de forma habitual en su territorio cuando hubiera permanecido en el mismo el mayor número de días del año inmediato anterior, contado de fecha a fecha, que finalice el día 
anterior al devengo del Impuesto $^{3}$, en las CCAA de régimen común dicho período es superior, pues se valorará considerando los cinco años inmediatos anteriores, también contados de fecha a fecha, que finalicen el día anterior al devengo ${ }^{4}$.

De este modo, la Ley 22/2009 ha optado por un plazo superior con el fin de evitar los cambios de residencia fraudulentos a los únicos efectos de conseguir una tributación menor, ya que la cesión del rendimiento del ISD también implica la aplicación de la normativa propia que hubiera aprobado la pertinente CCAA o territorio foral $y$, en algunos casos, puede resultar especialmente beneficiosa ${ }^{5}$.

De hecho, justamente por dicha finalidad, procede puntualizar que, a los efectos del mencionado cómputo, no será necesario que el causante hubiera pasado la mitad de los últimos cinco años más un día en una CCAA para que ésta resulte competente, sino que será suficiente con que no haya otra CCAA en la que hubiera permanecido más tiempo (de modo que los días que el causante hubiera pasado en el extranjero no computarán $)^{6}$. Y también a causa de la misma se establece que los cambios de residencia que tengan por objeto principal lograr una menor tributación efectiva no producirán efecto alguno, por lo que, si la Administración tributaria consigue probar que éste ha sido su fin, no deberán tenerse en cuenta ${ }^{7}$.

Sin embargo, procede precisar que, de acuerdo con el art. 25.Dos del Concierto económico, cuando el causante hubiera pasado el mayor número de días de los cinco años mencionados en una CCAA de régimen común pero hubiera permanecido en territorio vasco el mayor número de días del último año, también se cederá el rendimiento y la exacción del Impuesto a la correspondiente Diputación Foral pero se aplicarán las normas del pertinente territorio común (a no ser que el contribuyente hubiera conservado la condición política de vasco con arreglo al artículo 70.2 del Estatuto de Autonomía), lo mismo que en principio procederá cuando hubiera pasado el mayor lapso de tiempo de los últimos cinco años en el territorio de Navarra ${ }^{8}$ (motivo por el cual sería más que adecuado que el Convenio económico también adoptara previsiones en la

3 Art. 43.Uno.Primera del Concierto económico con el País Vasco y art. 8.2.1a.b) del Convenio económico con Navarra.

${ }_{5}^{4}$ Art. 28.1.1r.b) de la Ley 22/2009.

5 Al respecto, como ha señalado la DGT, lo que se pretende evitar son los cambios de residencia entre CCAA que respondan únicamente a motivaciones fiscales, en las que se manifieste la ausencia de vinculación con la nueva residencia formal. (Véanse, entre otras, las Respuestas a las Consultas vinculantes de la DGT V0256/2012, de 7 de febrero, y V1200/2012, de 31 de mayo).

${ }^{6}$ En este sentido, véase, entre otras, la Contestación a la Consulta Vinculante de la DGT V0443-16, de 4 de febrero.

7 Arts. 43.Siete del Concierto económico, 43.2 del Convenio económico y 28.4 de la Ley 22/2009.

${ }^{8}$ En concreto, así parece desprenderse de las SSTS de 13 de noviembre de 2014 y de 17 de noviembre de 2014, en las que se declara que, a los efectos del Concierto económico, en las relaciones entre los Territorios Históricos del País Vasco y la Comunidad Foral de Navarra, esta última debe considerarse "territorio común". 
misma línea, sin perjuicio de que lo más conveniente sería unificar el plazo de cinco años con carácter general -ya sea para evitar cambios de residencia fraudulentos, para simplificar la gestión del impuesto o para conseguir un mayor respeto al principio de igualdad-).

De todos modos, en el caso de Navarra, también se cederá el rendimiento cuando, teniendo el causante su residencia en el extranjero, conservara la condición política de navarro con arreglo al art. $5^{\circ}$ de la Ley Orgánica de Reintegración y Amejoramiento del Régimen Foral de Navarra, mientras que en el País Vasco también se cederá cuando, a pesar de que el causante tuviera su residencia en el extranjero, los contribuyentes la tuvieran en su territorio.

No obstante, con independencia de la cesión del rendimiento del Impuesto conforme a los criterios expuestos, procede añadir finalmente que, de acuerdo con la Disposición adicional segunda en la LISD, en las transmisiones mortis causa, también resultará de aplicación la normativa de las CCAA de régimen común si el causante hubiera sido residente en un Estado miembro de la UE o del Espacio Económico Europeo (EEE) distinto de España (procediendo la normativa de la CCAA en la que se encontrara el mayor valor de los bienes y derechos del caudal relicto situados en España o, si no los hubiera y el sujeto pasivo residiera en España, la de la correspondiente (CAA), así como en el caso de que el causante hubiera sido residente en una CCAA pero los contribuyentes residieran en un Estado miembro de la UE o del EEE distinto a España (caso en el que se aplicará pertinente la normativa autonómica).

No obstante, en estos últimos supuestos, debe puntualizarse que únicamente se cederán las competencias normativas (por lo que será el Estado a quien corresponderá el rendimiento del Impuesto y las pertinentes competencias de aplicación y revisión), aunque también resultarán de aplicación los mismos requisitos de determinación de la residencia habitual que establece el art. 28.1.10.b) de la Ley 22/2009.

Asimismo, procede recordar que tales previsiones se introdujeron en la LISD como consecuencia de la STJUE de 3 de septiembre de 2014 (asunto C-127/12), la cual declaró el incumplimiento de España del Derecho de la UE a la hora de fijar los puntos de conexión por la Ley 22/22009 (al establecer «diferencias [injustificadas y, por ende, discriminatorias] en el trato fiscal de las donaciones y las sucesiones entre los causahabientes y los donatarios residentes y no residentes en España, entre los causantes residentes y no residentes en España y entre las donaciones y las disposiciones similares de bienes inmuebles situados en territorio español y fuera de éste»).

Sin embargo, debe resaltarse la insuficiencia de estas nuevas previsiones, ya que, sin ir más lejos, aún resta pendiente la discriminación que reciben los sujetos que residen fuera de la UE y el EEEE (punto en el que, como ocurre en el País Vasco, debería hacerse referencia al extranjero), y es que, de conformidad con el art. 63 del TFUE, "quedan prohibidas todas las restricciones a los movimientos de capitales entre 
Estados miembros", pero también aquellas que puedan producirse "entre Estados miembros y terceros países" ${ }^{\prime \prime}$.

Así pues, considerando que en la cesión del ISD también deberá acudirse a la determinación de la residencia habitual (ya sea del causante o del adquirente), también deberá tenerse en cuenta a tal efecto la estancia en una residencia geriátrica (por ser el lugar donde se permanece y reside de forma efectiva), y más considerando que, a efectos de empadronamiento, la ubicación de la residencia también constituirá el domicilio de los residentes con carácter general ${ }^{10}$.

\section{IMPLICACIÓN EN LA REDUCCIÓN DE LA BASE IMPONIBLE POR LA TRANSMISIÓN DE LA VIVIENDA HABITUAL DEL CAUSANTE}

El siguiente de los aspectos del ISD en el que las residencias geriátricas pueden tener una clara implicación es en relación con la reducción de la base imponible por la adquisición de la vivienda habitual del causante, la cual se encuentra regulada en el art. 20.2.c) de la LISD.

Así, siempre que la misma sea objeto de adquisición por parte de su cónyuge, ascendientes o descendientes, o bien por parte de un pariente colateral mayor de 65 años con el que hubiese convivido durante los dos años anteriores a su fallecimiento, cada adquirente se podrá reducir en la pertinente base imponible un $95 \%$ del valor neto de la vivienda de acuerdo con el derecho sobre la misma que se le transmita (propiedad, nuda propiedad, usufructo, etc. -es decir, practicándose la reducción sobre el valor del derecho relativo a la vivienda que vaya a adquirir-), de modo que dicho porcentaje se aplicará sobre el valor de la vivienda una vez deducidas las cargas o gravámenes de naturaleza perpetua, temporal

${ }^{9}$ Entre muchos otros, véase un estudio crítico sobre la solución por la que ha optado España en MARTÍN QUERALT, J.: "El Impuesto sobre Sucesiones y Donaciones: de la vulneración del Derecho comunitario a la mera inconstitucionalidad", Tribuna Fiscal, 275, 2014; FALCÓN Y TELLA, R.: "El impuesto sobre sucesiones y donaciones y la libre circulación de capitales: una enmienda insuficiente", Quincena fiscal, 18, 2014; SIMÓN ACOSTA, E.: "Incompatibilidad del Impuesto sobre Sucesiones y Donaciones con el ordenamiento comunitario", Actualidad Jurídica Aranzadi, 891, 2014; ESCRIBANO LÓPEZ, F.: "Libertad de establecimiento y libre circulación de capitales: la proscripción de diferencias de tratamiento tributario por razón de residencia dentro de la UE de sujetos y objetos en el ISD español", en Derechos fundamentales y Hacienda Pública: una perspectiva europea, Cívitas, Madrid, 2015; CALVO VÉRGEZ, J.: "¿Se adapta la reforma de los puntos de conexión del ISD acometida a través de la aprobación de la Ley 26/2014, de 27 de noviembre, a los dictados de la Sentencia del TJUE de 3 de septiembre de 2014?", en Derecho y fiscalidad de las sucesiones "mortis causa" en España: una perspectiva multidisciplinar, Aranzadi, Cizur Menor, 2016; o RAMOS PRIETO, J.: "La tributación de las sucesiones mortis causa en España: una visión general desde la perspectiva del Derecho interno y del Derecho de la Unión Europea", en Derecho y fiscalidad de las sucesiones "mortis causa" en España: una perspectiva multidisciplinar, Aranzadi, Cizur Menor, 2016.

10 De hecho, como señala la STSJ de Cataluña 64/2015, de 22 de enero de 2015, «debe entenderse como algo regular y ordinario la modificación de los datos del padrón de los residentes de los geriátricos para facilitar la obtención de atención médica y la comodidad de estas gestiones, precisamente tratándose de un fase del ciclo vital en la que tanta importancia tienen estas cuestiones que podrían considerarse de mera logística», y es que «es de sobra conocido que la asignación de los centros de salud se realiza en función de la dirección de empadronamiento». 
o redimible que aparezcan directamente establecidos sobre la misma, así como la parte proporcional de deudas y gastos generales que formen parte del caudal relicto ${ }^{11}$.

No obstante, conforme la normativa estatal, existe una doble limitación para su aplicación: por una parte, que la reducción que se practique no exceda de $122.606,47$ euros para cada sujeto pasivo que tenga derecho a la misma $y$, por otra parte, que los adquirentes mantengan la vivienda en su patrimonio durante los diez años siguientes a la defunción del causante (salvo que fallezcan dentro de ese plazo).

Sin embargo, procede recordar que, conforme el art. 48 de la Ley $22 / 2009$, las CCAA de régimen común pueden mejorar las reducciones de la base imponible del ISD previstas por la LISD (supuesto en el que, cuando resulte de aplicación su normativa, las sustituirán), lo que ha tenido lugar en relación con la reducción aquí estudiada por parte de todas las autonomías excepto Castilla y León, Castilla-La Mancha, Extremadura y la Región de Murcia.

En concreto, las principales diferencias que han establecido respecto a la normativa estatal han sido para ampliar los sujetos que podrán tener acceso a la misma, para incrementar el porcentaje de reducción, para aumentar el límite cuantitativo al respecto y, por último, para reducir el tiempo requerido de mantenimiento de la vivienda en el patrimonio del adquirente, aunque, a los efectos que aquí interesan, también algunas han contemplado previsiones especiales para los casos en los que el causante hubiera estado viviendo en una residencia geriátrica en el momento de su muerte.

Y es que procede analizar si, en tales casos, procederá la mencionada reducción, punto en el que la LISD no contempla nada al respecto ni define qué deberá entenderse por vivienda habitual. No obstante, sí que lo hizo el epígrafe 1.4.b) de la Resolución 2/1999, el cual señaló expresamente que, «para la determinación de lo que ha de entenderse por vivienda habitual, hay que acudir al artículo 51 del Reglamento del Impuesto sobre la Renta de las Personas Físicas, aprobado por el Real Decreto 214/1999, de 5 de febrero [actual art. 41.bis del Real Decreto 439/2007, de 30 de marzo, por el que se aprueba el Reglamento del Impuesto sobre la Renta de las Personas Físicas y se modifica el Reglamento de Planes y Fondos de Pensiones (RIRPF), aprobado por Real Decreto 304/2004, de 20 de febrero], que es el que define dicho concepto en el ámbito fiscal».

Así, señala el primer apartado del mencionado precepto que se considerará vivienda habitual del contribuyente "la edificación que constituya su residencia durante un plazo continuado de, al menos, tres años", aunque, como añade, "se entenderá que la vivienda tuvo el carácter de habitual cuando, a pesar de no haber transcurrido dicho plazo, se produzca el fallecimiento del contribuyente 0 concurran otras

${ }^{11}$ En concreto, así lo señala el epígrafe 1.4 .d) de la Resolución $2 / 1999$, de 23 de marzo, de la DGT, relativa a la aplicación de las reducciones en la base imponible del Impuesto sobre Sucesiones y Donaciones, en materia de vivienda habitual y empresa familiar. 
circunstancias que necesariamente exijan el cambio de domicilio, tales como celebración de matrimonio, separación matrimonial, traslado laboral, obtención del primer empleo, o cambio de empleo, u otras análogas justificadas".

Sin embargo, como ha puntualizado la DGT, la excepción del necesario plazo de tres años para que una vivienda pueda tener la consideración de habitual «implica únicamente que se consolidan las deducciones anteriormente practicadas o que, si la vivienda se transmitiese en dicho momento, se podría aplicar el beneficio fiscal de la exención por reinversión en otra vivienda habitual o por transmisión por personas mayores de 65 años, pero, una vez transcurridos los tres años de residencia, la vivienda sólo tendrá el carácter de habitual mientras en ella mantenga su residencia el propietario, perdiendo ese carácter a partir del momento en que deje de residir en la misma, cualquiera que sea su causa» ${ }^{12}$.

Así pues, parece que si el causante se encontraba residiendo en una residencia geriátrica, la que había sido su vivienda habitual habría perdido tal condición $y$, en consecuencia, no procedería la reducción del art. 20.2.c) de la LISD por su adquisición mortis causa, aunque el TS ha dictado la STS 841/2017, de 12 de mayo, en unificación de doctrina, señalando que, curiosamente, el inmueble no habría perdido tal condición si hubiera sido trasladado a la vivienda del causahabiente por razones de enfermedad (lo mismo que puede predicarse respecto a las residencias geriátricas).

De este modo, el TS se acoge a las "otras causas análogas justificadas" del traslado que, según el art. 41.bis del RIRPF, no hacen perder al inmueble la consideración de vivienda habitual para entender que, dentro de las mismas, «ha de incluirse la enfermedad acreditada que obliga al cambio de residencia, máxime cuando el fallecimiento sobreviene durante y como consecuencia de dicha enfermedad».

Pero es que, además, no sólo declara que el traslado desde la vivienda habitual de un causante a la vivienda de su hermano debido a motivos de salud, producido más de tres años antes de su fallecimiento, no hace perder la condición de vivienda habitual al inmueble en el que residía el causante antes de que se mudara, sino también que la convivencia con el mismo en casa del hermano habilita a este último para aplicarse la reducción del art. 20.2.c) de la LISD al entender también cumplido el requisito de convivencia a pesar de no materializarse en la vivienda transmitida.

No obstante, como se ha señalado, el art. 41.bis del RIRPF es claro al establecer que la excepción que contempla ante los cambios de domicilio forzosos se da la hora de considerar como habitual la vivienda en la que

\footnotetext{
12 Contestación de la Consulta Vinculante de la DGT V1930-07, de 14 de septiembre, la cual entendió justamente que la que había sido la vivienda habitual de la causante hasta que tuvo que ser trasladada al domicilio de uno de sus hijos por razones graves de salud (donde residió los últimos siete años) había perdido tal carácter a efectos de la reducción del art. 20.2.c) de la LISD. En la misma línea, pueden verse otras resoluciones a consultas como la V0132-04, de 24 de septiembre, o la 0672-03, de 20 de mayo.
} 
no hubiera transcurrido el plazo de tres años de residencia (validando así la procedencia de operaciones realizadas que requirieran tal carácter como puede ser a efectos de la exención por reinversión en la vivienda habitual-), pero no a la hora de seguir manteniéndole tal condición para las operaciones que se realicen de cara al futuro a pesar de su no ocupación.

De hecho, justamente por ello, después de que el apartado 3 del mismo art. 41.bis prevea que "se entenderá que el contribuyente está transmitiendo su vivienda habitual cuando, con arreglo a lo dispuesto en este artículo, dicha edificación constituya su vivienda habitual en ese momento o hubiera tenido tal consideración hasta cualquier día de los dos años anteriores a la fecha de transmisión", limita específicamente tales consideraciones "a los exclusivos efectos" de la aplicación de las exenciones previstas en los artículos 33.4. b) y 38 de la $\operatorname{LIRPF}^{13}$, de modo que no pueden extrapolarse al art. 20.2.c) de la LISD.

Por consiguiente, con base en la normativa estatal, no parece aplicable la reducción aquí estudiada si el causante, en el momento de su muerte, se encontraba residiendo en una residencia geriátrica, y no hay que olvidar en este punto que, tanto el TS como la Administración tributaria, en cuanto que órganos públicos, se encuentran plenamente sometidos al estricto cumplimiento de la misma.

No obstante, conviene precisar que tales consideraciones son predicables respecto a la LISD, ya que, si resulta de aplicación una normativa autonómica que hubiera previsto la procedencia de la reducción a pesar de que el causante no se encontrara residiendo de forma efectiva en la pertinente vivienda (mejorando, de este modo, la reducción estatal), sí que resultará de aplicación.

$Y$ esto ha tenido lugar en diversas CCAA aunque de forma diferente, concretamente en Canarias, Galicia y Cataluña. Así, en el caso canario, se señala que, si el causante hubiera tenido su último domicilio en un centro residencial o socio-sanitario, la reducción aquí estudiada podrá aplicarse sobre aquella vivienda en la que efectivamente hubiera tenido su residencia habitual inmediatamente antes de su cambio de domicilio al citado centro ${ }^{14}$, mientras que Galicia apunta que se entenderá que la última vivienda habitual en la que residió el causante no ha perdido tal carácter cuando, por circunstancias físicas o psíquicas, se hubiera trasladado a un centro especializado para recibir cuidados (añadiendo

13 En concreto, tales exenciones son relativas, respectivamente, a la exención de las ganancias patrimoniales que se pongan de manifiesto con ocasión de la transmisión de su vivienda habitual por mayores de 65 años o por personas en situación de dependencia severa o de gran dependencia (de conformidad con la Ley de promoción de la autonomía personal y atención a las personas en situación de dependencia), y a la exención de las ganancias patrimoniales obtenidas por la transmisión de la vivienda habitual del contribuyente, siempre que el importe total obtenido por la transmisión se reinvierta en la adquisición de una nueva vivienda habitual.

${ }_{14}$ Art. 22 -ter.3 del Decreto Legislativo 1/2009, de 21 de abril, por el que se aprueba el Texto Refundido de las disposiciones legales vigentes dictadas por la Comunidad Autónoma de Canarias en materia de tributos cedidos. 
también en este caso que tampoco perderá tal condición cuando, por las mismas circunstancias, se hubiera trasladado a vivir con los familiares incluidos en el grupo de parentesco que da derecho a obtener la reducción del art. 20.2.c) de la LISD) ${ }^{15}$.

Por su parte, Cataluña también ha adoptado su normativa en este sentido, estableciendo que, si el causante, en la fecha de su muerte, hubiera tenido su residencia efectiva en un domicilio del que no era titular, tendrá la consideración de vivienda habitual la que tenía esta condición hasta cualquier día de los diez años anteriores a la fecha de la muerte, aunque si hubiera tenido su último domicilio en un centro residencial o socio-sanitario, no se aplicará ningún límite temporal para dicha consideración ${ }^{16}$.

Finalmente, el estudio de la reducción en los supuestos aquí realizados también requiere hacer una breve referencia a la normativa foral (punto en el que procede recordar que el ISD es un tributo concertado de normativa autónoma), donde cabe señalar que, si bien Navarra no ha adoptado ninguna previsión al respecto, sí que lo han hecho los tres territorios históricos forales del País Vasco contemplando diferencias substanciales respecto a la estatal.

En concreto, los territorios vascos han optado por no supeditar la aplicación de la reducción a ninguna relación de parentesco con el causante, sino requiriendo únicamente la convivencia efectiva con el mismo durante los dos años anteriores a su fallecimiento (eliminando, al mismo tiempo, la obligación de mantener en la vivienda en el patrimonio del adquirente durante un cierto período de tiempo) ${ }^{17}$.

Por consiguiente, en estos territorios, si el causante hubiera permanecido en una residencia geriátrica, quedará desvirtuado el requisito de la convivencia señalado y resultará imposibilitada la aplicación de la mencionada reducción, igual que técnicamente debería suceder si resulta de aplicación la LISD o la normativa de las CCAA de régimen común excepto en el caso de Canarias, Galicia y Cataluña.

Sin embargo, considerando que la finalidad de dicha reducción se basa tanto en el derecho a disfrutar de una vivienda digna y adecuada (art. 47 de la CE) como en la protección social, económica y jurídica de la familia (art. 39 de la $\mathrm{CE})^{18}$, parece que, incluso en los casos donde el causante

15 Art. 7.Tres.1 del Decreto Legislativo 1/2011, de 28 de julio, por el que se aprueba el Texto Refundido de las disposiciones legales de la Comunidad Autónoma de Galicia en materia de tributos cedidos por el Estado.

${ }^{16}$ Art. 18.3 de la Ley 19/2010, de 7 de junio, de regulación del Impuesto sobre Sucesiones y Donaciones.

17 Art. 22.8 de la Norma Foral de Álava 11/2005, de 16 de mayo, del Impuesto sobre Sucesiones y Donaciones; art. 19.1 de la Norma Foral 3/1990, de 11 de enero, del Impuesto sobre Sucesiones y Donaciones del Territorio Histórico de Guipúzcoa; y art. 44 de la Norma foral de Vizcaya 4/2015, de 25 de marzo, del Impuesto sobre Sucesiones y Donaciones.

${ }^{18}$ En concreto, así constaba en la Exposición de Motivos del Real Decreto-Ley 7/1996, de 7 de junio, sobre medidas urgentes de carácter fiscal y de fomento y liberalización de la actividad económica, con el que se incorporó tal reducción en la regulación del ISD, señalándose específicamente que con la misma se pretendía "aliviar el coste fiscal derivado 
hubiera pasado a habitar en una residencia geriátrica, su mantenimiento seguirá siendo susceptible de garantizar ambos objetivos, especialmente en aquellos supuestos donde los adquirentes vivan de forma efectiva en el inmueble que van a recibir y deban hacer frente a la pertinente tributación.

$Y$ todo ello sin olvidar que, respecto a los ascendientes, descendientes y cónyuges, no se exige ni que convivieran con el causante ni que tuvieran fijada en el inmueble transmitido su vivienda habitual, por lo que negarles de la reducción por el simple hecho de que el transmitente hubiera permanecido en una residencia de ancianos y permitírsela si seguía habitando en el mismo sin que los adquirentes convivieran con él e incluso tuvieran una vivienda habitual propia (pudiendo aplicar así la reducción tantas veces como viviendas habituales reciban) vulnera claramente los principios de igualdad y generalidad tributarios, sin que se halle razón ninguna que permita su justificación.

Además, procede resaltar por último que la relevancia de la reducción aquí estudiada no es menor, sino que, aparte de la gran cuantía que puede liberar de imposición ${ }^{19}$, conlleva otras importantes ventajas respecto al pago de la cuota tributaria derivada de la transmisión de la vivienda (concretamente, conforme al art. 39 de la LISD, en relación con su aplazamiento -que podrá ser de 5 años- y fraccionamiento -de 10 pagos semestrales transcurrido el plazo anterior-).

\section{IMPLICACIÓN EN EL CÁLCULO DEL AJUAR DOMÉSTICO}

Por su parte, el siguiente de los aspectos en los que debe analizarse la incidencia de las residencias geriátricas en la tributación de las adquisiciones mortis causa es el relativo al ajuar doméstico, el cual, de conformidad con el art. 15 de la LISD, formará parte de la masa hereditaria. Por consiguiente, deberá incluirse en la base imponible del ISD valorándose en el $3 \%$ del importe del caudal relicto del causante, a no ser que los interesados le asignen un valor superior o prueben fehacientemente, por cualquier medio válido en Derecho, que su importe es inferior 0 , directamente, inexistente.

De este modo, como destaca TOVILLAS, estamos ante una doble presunción (la de la existencia del propio ajuar y la de su valoración mínima ${ }^{20}$ ), las cuales, a pesar de su posible justificación en términos antielusorios y de practicabilidad, han sido ampliamente criticadas por la

de la transmisión mortis causa (...) de la vivienda habitual, cuando dicha transmisión se efectuase en favor de ciertas personas allegadas al fallecido".

${ }^{19}$ Al respecto, y aunque la LISD fije una reducción del $95 \%$ del valor de la vivienda, algunas CCAA lo han incrementado hasta el $100 \%$, como es el caso de las Islas Baleares (art. 23 del Decreto Legislativo 1/2014, de 6 de junio, por el que se aprueba el Texto Refundido de las Disposiciones Legales de la Comunidad Autónoma de las Illes Balears en Materia de Tributos Cedidos por el Estado).

20 J.M. TOVILLAS MORÁN, "El Régimen jurídico del ajuar doméstico en la reciente jurisprudencia", Revista Fiscal y Laboral al Día, 162, 2008, p. 25. 
doctrina por su cuestionable respeto a los principios de justicia tributaria ${ }^{21}$.

En cualquier caso, como ha precisado la DGT, la base sobre la que deberá aplicarse el 3\% para el cálculo del ajuar doméstico es el importe total del caudal relicto, entendiendo por tal el conjunto total de bienes y derechos incluidos en la masa hereditaria, «es decir, el valor real de los bienes y derechos pertenecientes al causante, minorado por las cargas y gravámenes deducibles conforme a la LISD, pero sin tener en cuenta las deudas del causante» ${ }^{22}$ (punto en el que tampoco afectará la reducción que, en su caso, pudiera aplicarse por la adquisición de su vivienda habitual del mismo) ${ }^{23}$.

Asimismo, tras señalar que, para el cálculo del ajuar doméstico, tampoco se incluirán los bienes adicionados, las donaciones acumuladas y los seguros sobre la vida (ya fueran contratados por el causante, si el seguro fuera individual, o aquellos en los que figure como asegurado, si fuera colectivo), el art. 34.3 del RISD establece que el valor resultante se minorará en el de los bienes que, por disposición del art. 1.321 del Código Civil o de disposiciones análogas de Derecho civil foral o especial, deben entregarse al cónyuge sobreviviente (el denominado "ajuar de la vivienda habitual de los esposos"), cuyo importe se fijará, a efectos del ISD, en el $3 \%$ del valor catastral de la vivienda habitual del matrimonio (salvo que los interesados acrediten fehacientemente uno superior).

$Y$ en este punto, procede recordar que el mencionado precepto del Código Civil establece que, "fallecido uno de los cónyuges, las ropas, el mobiliario y enseres que constituyan el ajuar de la vivienda habitual común de los esposos se entregarán al que sobreviva, sin computárselo en su haber", excluyendo de dicho concepto "las alhajas, objetos artísticos, históricos y otros de extraordinario valor", por lo que parece desprenderse de la regulación mencionada que la figura del ajuar doméstico regulada en el ISD es más amplia.

\footnotetext{
${ }^{21}$ Al respecto, así lo pone de manifiesto HERRERA, quien señala que «estamos ante una norma de simplificación basada en consideraciones antidefraudatorias y de practicabilidad que restringe el derecho a contribuir con arreglo a la capacidad económica efectiva», ya que «el legislador tiene en cuenta la normal existencia de un cierto ajuar doméstico, difícil de inventariar y de imposible control por la Administración, y pretende someterlo a gravamen mediante un criterio de cuantificación a tanto alzado» (P.M. HERRERA MOLINA, Capacidad Económica y Sistema Fiscal. Análisis del ordenamiento español a la luz del Derecho alemán, Marcial Pons, Madrid, 1998, p. 253). Además, como añade PITA, este sistema puede dar lugar a que se llegue a someter a gravamen una capacidad económica inexistente, vulnerando, en consecuencia, los principios de justicia tributaria contenidos en el art. 31 de la CE (A.M. PITA GRANDAL, La prueba en el procedimiento de gestión tributaria, Marcial Pons, Madrid, 1998, p. 122).

${ }^{22}$ Contestación a la Consulta Vinculante de la DGT V0832-17, de 4 de abril de 2017.

${ }^{23}$ Véase en este punto la Contestación a la Consulta de la DGT 2009-03, de 1 de diciembre de 2003, donde se constata la desvinculación entre el ajuar doméstico (concepto que, como señala, «alude no sólo a muebles incluidos en la vivienda sino también a los efectos personales del causante») y la determinación del valor con el que la vivienda habitual se integra en la base imponible del causahabiente, aunque el ajuar se adicione para la determinación de su participación individual.
} 
No obstante, cierto es que la LISD no precisa qué elementos integran el ajuar doméstico ni define su concepto (sino que se limita a establecer su valoración por regla general con el porcentaje mencionado), aunque el art. 34.2 del RISD se remite a las reglas para su valoración establecidas en el Impuesto sobre el Patrimonio (IP) si de su aplicación resulta un valor superior al del cálculo del 3\% (a no ser que se pruebe su inferior importe $)^{24}$.

Por ello, partiendo de la vinculación del ajuar doméstico del ISD al del IP, la propia DGT han considerado pertinente la extensión del concepto que realiza este último (eximiéndolo de gravamen) al ámbito del impuesto sucesorio, entendiendo que, de acuerdo con el art. 4.4 de la Ley 19/1991, de 6 de junio, del Impuesto sobre el Patrimonio (LIP), constituyen el ajuar doméstico "los efectos personales y del hogar, utensilios domésticos y demás bienes muebles de uso particular del sujeto pasivo, excepto los bienes a los que se refieren los artículos 18 [joyas, pieles de carácter suntuario y vehículos, embarcaciones y aeronaves] y 19 [objetos de arte y antigüedades] de esta Ley" ${ }^{25}$.

Sin embargo, algunas sentencias han limitado los elementos que pueden integrar el ajuar doméstico en el ISD «al conjunto de bienes que sirven para hacer frente a las necesidades y eventualidades derivadas del uso doméstico y personal de los causantes y que se ubican en los inmuebles que forman parte del caudal hereditario» ${ }^{26}$, mientras que otras, como la STS 1877/2016, de 20 de julio de 2016 (que sentó en unificación de doctrina que, en su cómputo automático establecido por la LISD y el RISD, se deben incluir todos los bienes que integran el caudal relicto y no únicamente los que guardan relación con el ajuar), entienden que la referencia de la LISD al "caudal relicto" y del RISD a la "masa hereditaria" al regularlo, parecen conllevar que en el ISD existe un concepto de ajuar doméstico propio y autónomo dada «la configuración propia y autónoma

${ }^{24}$ Esta remisión, hasta el día 1 de enero de 1992, la hacía el propio art. 15 de la LISD sin prever el cálculo automático del 3\% (por el cual se acabó optando debido a la dificultad que entraña su determinación), precepto que, justamente, fue modificado por la Disposición adicional tercera de la LIP.

${ }^{25}$ Al respecto, así consta expresamente en la Contestación a la Consulta Vinculante de la DGT V0832-17, de 4 de abril de 2017, donde, tras recordar que fue la Disposición adicional tercera de la LIP la que modificó el art. 15 de la LISD, señala que «de esta forma se trasladó al ámbito del Impuesto sobre Sucesiones y Donaciones un concepto del ajuar doméstico que queda exento en el Impuesto sobre el Patrimonio por el artículo 4 de su Ley reguladora, fijándose una regla de cálculo debido a la dificultad que entraña su determinación, si bien permitiendo al sujeto pasivo que fije otro valor o que demuestre su inexistencia». Por consiguiente, como resalta la Contestación a la Consulta de la DGT 200903, de 1 de diciembre de 2003, el concepto de ajuar doméstico en el ISD «alude no sólo a muebles incluidos en la vivienda sino también a los efectos personales del causante» $y$, en consecuencia, puede seguir existiendo a pesar de que se le reste el importe el ajuar de la vivienda habitual de los esposos.

${ }^{26}$ STS de Asturias 697/2017 el 31 de julio de 2017. En un sentido similar, entre muchas otras, véase la STSJ Madrid 1816/2002, de 18 de julio de 2002, la cual entiende que la inclusión del ajuar doméstico está dirigida a aquellos bienes de la herencia que por su naturaleza, como los inmuebles, pudieran llevar incorporada su transmisión. 
que respecto de determinadas instituciones puede establecer el Derecho Tributario, e incluso un impuesto concreto ${ }^{27}$.

De hecho, teniendo en cuenta los diferentes criterios jurisprudenciales, el propio TS ha admitido un recurso de casación a los efectos de determinar qué elementos o bienes deben entenderse incluidos dentro de su concepto sobre el que se establece su presunción en el art. 15 de la LISD ${ }^{28}$, detallando «si resulta de aplicación el concepto civil de "ajuar de la vivienda habitual" al ámbito del impuesto sobre sucesiones; si es admisible la extensión a dicho impuesto del concepto de ajuar del impuesto sobre al patrimonio; o si la noción tributaria de "ajuar doméstico" tiene un superior alcance conceptual respecto del indicado concepto civil, dando lugar a la existencia de uno propio en el ámbito del impuesto sobre sucesiones que sobrepase la noción contenida tanto en el artículo 1321 CC como en el 15 LIP».

De todos modos, partiendo de la normativa mencionada, procede analizar en este caso cómo deberá procederse en el caso de que el causante hubiera estado residiendo en la habitación de una residencia geriátrica, punto en el que el propio TS ya dejó claro que también en este supuesto podía existir ${ }^{29}$. Por consiguiente, como ha señalado la DGT, también en tales casos deberá presumirse por defecto su existencia calculándolo como se ha señalado, aunque, teniendo en cuenta que se trata de una presunción iuris tantum, los interesados podrán destruirla si prueban de forma fehaciente su menor valor o su inexistencia ${ }^{30}$.

En concreto, dicha enervación se deberá practicar mediante una prueba válida en Derecho cuyo valor deberá apreciar el órgano de gestión tributaria ante el que se presente la oportuna autoliquidación o practique la pertinente liquidación ${ }^{31}$, de modo que, también en tales supuestos, si el

27 STS 1877/2016, de 20 de julio de 2016. En la misma línea, véase, entre otras, las SSTS de Madrid 223/2014, de 13 de febrero, 106/2015, de 5 de febrero o 131/2017, de 23 de febrero de 2017, e incluso la Resolución del TEAC de 11 de junio de 2015, quien parece pronunciarse en el mismo sentido al señalar que «la Ley vincula a la propia persona del causante y a las exigencias derivadas de la atención de sus necesidades de todo tipo la existencia, salvo prueba en contrario, de un ajuar de bienes muebles de valor proporcionado al valor económico global atribuible al conjunto del resto de su patrimonio, sin establecer diferenciación o discriminación alguna por razones de la concreta naturaleza de los bienes y derechos en que se materialice en cada caso dicho patrimonio restante».

${ }^{28}$ Recurso admitido por el ATS 2083/2008, de 29 de enero de 2018.

29 Al respecto, como señaló la STS de 26 de abril de 1995, el ajuar doméstico es el «conjunto de ropas, muebles, enseres, utensilios, etc. necesarios para la vida humana existe en todo caso», por lo que, incluso en el supuesto del «anciano residente en un hotel o un centro de acogimiento, hay ajuar doméstico constituido por ropas, enseres, utensilios y otros bienes de su uso cotidiano». Y es que, a pesar de que dicha sentencia era referida a la regulación del ajuar en el Impuesto Extraordinario sobre el Patrimonio, la doctrina establecido al respecto es perfectamente aplicable al ISD, tal y como ha determinado el propio TEAC en Resoluciones como las de 26 de mayo y 23 de junio de 2004. Asimismo, se ha reconocido en sentencias como la STSJ de Madrid 223/2014, de 13 de febrero, donde se señala que «el ajuar no se hace depender de la titularidad de bienes inmuebles urbanos, pues una persona puede carecer de ellos y vivir en una residencia, y tener, en cambio, las ropas y enseres de uso cotidiano que conforman el ajuar».

${ }^{30}$ Contestación a la Consulta Vinculante de la DGT V0512-06, de 28 de marzo de 2006.

${ }^{31}$ Contestación a la Consulta Vinculante de la DGT V1002-12, de 9 de mayo de 2012. 
ajuar doméstico no se hubiera incluido en el inventario de los bienes relictos del causante y no se hubiera acreditado su inexistencia, se deberá adicionar de oficio para determinar la base imponible de cada causahabiente (art. 34.1 del RISD).

Sin embargo, como ha reconocido la propia jurisprudencia, «es muy difícil probar la inexistencia [del ajuar] y menos aún de forma fehaciente ${ }^{32}$, y más considerando la diversidad de opiniones en cuanto a su concepto mientras el TS no se pronuncia al respecto.

Así, a modo de ejemplo, puede resaltarse que, mientras el TSJ de Madrid consideró probada su inexistencia por el hecho de que el único elemento de la masa hereditaria era una cuenta corriente (entendiendo que la inclusión del ajuar doméstico está dirigida a aquellos bienes de la herencia que por su naturaleza, como los inmuebles, pudieran llevar incorporada su transmisión) ${ }^{33}$, el mismo Tribunal sostuvo que por el «mero hecho de que la causante viviera en una residencia de ancianos y no tuviera más bienes que un dinero depositado en el banco, sin que tuviera bienes inmuebles, no es posible deducir, sin más, que no tenía ajuar doméstico» (razonando que el ajuar no se hace depender de la titularidad de bienes inmuebles urbanos, ya que una persona puede carecer de ellos y vivir en una residencia, y tener, en cambio, las ropas y enseres de uso cotidiano que lo conforman) ${ }^{34}$.

De todos modos, lo que sí parece claro es que, aunque se demuestre que el causante residía en una residencia geriátrica, no se desvirtuará, sin más, la existencia de ajuar doméstico, sino que también deberá acreditarse que carecía de bienes muebles, ropas o enseres propios ${ }^{35}$.

\section{IMPLICACIÓN EN LA BONIFICACIÓN DE LA CUOTA POR LA RESIDENCIA EN CEUTA O MELILLA}

Finalmente, el último de los aspectos de la tributación en el ISD de las adquisiciones mortis causa en los que podrá tener incidencia la

${ }^{32}$ STSJ Comunidad Valenciana 881/2001, de 2 de julio de 2001.

33 STS Madrid 1816/2002, de 18 de julio de 2002.

${ }^{34}$ STSJ Madrid 475/2016, de 5 de mayo de 2016.

35 A modo de ejemplo, respecto a causantes que residían en una residencia geriátrica, puede señalarse que se ha considerado probada la inexistencia de ajuar doméstico, aunque partiendo de diversos criterios acerca del mismo, por el hecho de acreditar que el difunto había vivido en un hotel los ocho años anteriores a su fallecimiento y en una residencia los últimos meses y que no poseía ningún bien inmueble (entendiendo que los elementos propios para su vida, como la ropa de uso común o elementos de aseo, deben entenderse como valores económicos individuales que no pueden conllevar la inclusión automática del ajuar -STSJ de Galicia 394/2012, de 4 de junio-), por haberse desprendido del mismo (o, al menos, de una buena parte) regalándolo a diferentes personas al trasladarse a la residencia de ancianos (STJS de Castilla y León 305/2001, de 30 de junio de 2001 -probando el desprendimiento mediante la prueba testifical de dos de las donatarias-), por acreditar mediante informe emitido por la representante de la residencia que el causante no poseía ningún bien mueble ni ropas de uso común de la casa, que eran suministradas por la residencia, junto a la ausencia de bienes inmuebles en el caudal relicto (STSJ Cataluña 268/2001, de 27 de marzo de 20101) o por haber transmitido la vivienda habitual, junto con los muebles, diez años antes del fallecimiento del causante y sin que se reservara derecho alguno sobre la misma, al pasar a residir en un residencia (STSJ de Cantabria $1106 / 2017$, de 28 de junio de 2017). 
permanencia en una residencia geriátrica será respecto a la bonificación de la cuota que prevé el art. 23. bis de la LISD, donde se señala que, si el causante hubiera tenido su residencia habitual a la fecha del devengo en Ceuta o Melilla, se efectuará una bonificación del $50 \%$ de la cuota.

No obstante, dicha bonificación (que, junto a las adquisiciones mortis causa, se aplicará a las cantidades percibidas por los beneficiarios de seguros sobre la vida que se acumulen al resto de bienes y derechos que integran la porción hereditaria del beneficiario), se elevará al 99\% cuando los causahabientes sean descendientes, adoptados, el cónyuge, ascendientes o adoptantes del causante.

De todos modos, conforme al apartado 4, procede destacar que también en este caso se determinará la residencia habitual conforme a las normas y puntos de conexión establecidos en la actual Ley 22/2009, aunque no se exigirá que el causante hubiera residido en Ceuta o Melilla el mayor número de días del período de los cinco años anteriores, contados fecha a fecha, que finalicen el día anterior al del devengo, sino que hubiera tenido su residencia en los mencionados territorios durante este período.

Así pues, por las razones ya apuntadas al analizar la cesión del Impuesto, también se considerará a tales efectos la estancia del causante en las residencias geriátricas que estuvieran situadas en tales ciudades (con independencia de donde hubiera estado radicada su vivienda habitual antes de su ingreso), por ser en las mismas donde realmente permanecía y residía de forma efectiva.

\section{IMPLICACIÓN EN LA POTESTATIVA BONIFICACIÓN DE LA CUOTA ÍNTEGRA DEL IIVTNU DERIVADA DE LA ADQUISICIÓN MORTIS CAUSA DE LA VIVIENDA HABITUAL DEL CAUSANTE}

Finalmente, la completa valoración de la incidencia de las residencias geriátricas en la tributación de las adquisiciones mortis causa requiere analizar la potestativa bonificación en la cuota íntegra del IIVTNU por las transmisiones de terrenos, y la transmisión o constitución de derechos reales de goce limitativos del dominio, realizadas a título lucrativo por causa de muerte.

Así, en el ámbito del mencionado impuesto municipal, establece el art. 108.4 del TRLRHL que "las ordenanzas fiscales podrán regular una bonificación de hasta el 95 por ciento de la cuota íntegra del impuesto, en las transmisiones de terrenos, y en la transmisión o constitución de derechos reales de goce limitativos del dominio, realizadas a título lucrativo por causa de muerte a favor de los descendientes y adoptados, los cónyuges y los ascendientes y adoptantes", si bien algunos entes locales han limitado dicha deducción a que el bien en cuestión sea la vivienda habitual del causante ( $y$ es que las Corporaciones locales pueden condicionar la aplicación de dicha bonificación dentro de los límites que contempla el TRLRHL) ${ }^{36}$.

${ }^{36}$ Dicha posibilidad ha sido reconocida tanto por la DGT como por el propio TS, como puede comprobarse, respectivamente, en la Contestación a la Consulta de la DGT 0012-17, de 25 
Este, por ejemplo, es el caso de Valencia, donde se señala que, "cuando el incremento de valor se manifieste por causa de muerte, respecto de la transmisión de la propiedad de la vivienda habitual del causante, o de la constitución o transmisión de un derecho real de goce limitativo de dominio sobre la misma, a favor de los descendientes o ascendientes, por naturaleza o adopción, y del cónyuge", la cuota del impuesto se verá bonificada, en función del valor del suelo correspondiente a la vivienda, mediante la aplicación de distintos porcentajes reductores, con independencia del valor atribuido al derecho ${ }^{37}$.

Así pues, cada Ayuntamiento, además de fijar los pertinentes requisitos sustantivos y formales que, mediante ordenanza, le encomienda el art. 108.6 del TRLRHL, puede determinar los límites y condiciones para la procedencia de esta bonificación, siempre que no amplíen ni el ámbito objetivo ni el subjetivo delimitado por el art. 108.4 (ya que los beneficios fiscales deben venir establecidos por normas con rango de ley) ${ }^{38}$ y que no establezcan reducciones discriminatorias ni contrarias al deber general de contribuir de forma injustificada.

En relación con este último aspecto, las reducciones que se fijen deberán respetar el principio de igualdad ante la ley contemplado en el art. 14 de la $C E$, por lo que deberán superar el triple examen que el TC utiliza al respecto a la hora de determinar eventuales discriminaciones improcedentes: que los supuestos donde pueda cuestionarse la vulneración del mencionado derecho sean situaciones objetivamente comparables, que exista un fin objetivo, razonable y constitucionalmente válido que legitime su trato diferenciado, y que las consecuencias jurídicas derivadas del mismo sean razonables (en el sentido de que entre el medio empleado y la finalidad perseguida exista una relación de

de abril de 2017, y en la STS de 29 de mayo de 2008. Y del mismo modo, así lo ha entendido la mayor parte de la doctrina, como es el caso de QUESADA SANTIUSTE al señalar que "nada impide que la Ordenanza fiscal limite su ámbito de aplicación previendo, por ejemplo, que tan sólo será aplicable a los descendientes y ascendientes de primer grado de consanguinidad $\mathrm{o}$ cuando el sujeto pasivo acredite que sus rentas y patrimonios no excedan de cierta cuantía". (F. QUESADA SANTIUSTE, Impuesto sobre el Incremento de Valor de los Terrenos de Naturaleza Urbana, Bayer Hermanos, Barcelona, 2001, pág. 122).

${ }^{37}$ Art. 17 de la Ordenanza Fiscal 1.3 reguladora del Impuesto sobre el Incremento de Valor de los Terrenos de Naturaleza Urbana, aprobada por el Pleno del Ayuntamiento de Valencia el 30 de noviembre de 1989 (modificada por última vez por acuerdo de fecha 23 de diciembre de 2015).

${ }^{38}$ Al respecto, de conformidad con el art. 9.1 del propio TRLRHL, "no podrán reconocerse otros beneficios fiscales en los tributos locales que los expresamente previstos en las normas con rango de ley o los derivados de la aplicación de los tratados internacionales", por cuanto, junto a las exigencias de rango legal del art. 31.3 de la CE y el art. 8.d) de la LGT, opera el art. 133.3 de la CE (requiriendo el rango legal para establecer "todo beneficio fiscal que afecte a los tributos del Estado"). Y es que, si bien el TC, respecto a las exenciones y los beneficios fiscales, señaló que el alcance de dicha reserva no impera con carácter absoluto sino relativo (dejando fuera de sus exigencias los aspectos relacionados con su regulación y su reducción o supresión), consideró que su establecimiento o ampliación (como ocurriría en este caso) quedaba cubierto por el principio de legalidad (véase al respecto la STC 6/1983, de 4 de febrero). 
proporcionalidad, evitando los resultados especialmente gravosos o desmedidos) $)^{39}$.

Y de igual modo, tampoco podrán vulnerar los principios de justicia tributaria previstos en el art. 31.1 de la CE, quedando prohibidas todas las bonificaciones que, suponiendo una quiebra al derecho general de contribuir al sostenimiento de los gastos públicos, no respondan a fines de interés general que los justifiquen y no sean proporcionadas en el sentido de adecuadas al fin legítimo constitucionalmente perseguido ${ }^{40}$.

Por consiguiente, debe acudirse a la pertinente ordenanza de cada municipio para determinar si el hecho de que el causante habitara en una residencia geriátrica puede impedir su procedencia, como podría darse si se exigiera que éste permaneciera en la vivienda transmitida o si se requiriera su convivencia con el adquirente.

Sin embargo, es importante resaltar en este punto la improcedencia de limitar la aplicación de la bonificación al empadronamiento del causante y/o el transmitente en la vivienda en cuestión ${ }^{41}$, ya que, a pesar de que el art. 16.1 de la Ley 7/1985, de 2 de abril, Reguladora de las Bases del Régimen Local señale que los datos del padrón municipal "constituyen prueba de la residencia en el municipio y del domicilio habitual en el mismo" (excepto, como contempla el art. 18.2, para los extranjeros), y de que, como añade, "las certificaciones que de dichos datos se expidan tendrán carácter de documento público y fehaciente para todos los efectos administrativos" (dentro de los que, lógicamente, deben entenderse incluidos los tributarios), no son el único medio de prueba, en cuanto a realidad fáctica, del domicilio habitual.

Además, como añadió la STSJ de Cantabria 310/2017, de 6 de octubre, reconociendo justamente la improcedencia de dicha limitación,

${ }^{39}$ Entre otras, véase la consolidada doctrina del TC al respecto en las SSTC 46/1999, de 22 de marzo; 200/2001, de 4 de octubre; 39/2002, de 14 de febrero; o 96/2002, de 25 de abril.

${ }^{40}$ En este punto, véase, entre otras, las SSTC 96/2002, de 25 de abril; o 57/2005, de 14 de marzo. $Y$ es que, como señala HERNÁNDEZ GUIJARRO, "el mandato constitucional de llamar a todos al sostenimiento de los gastos públicos, va también dirigido a potestad tributaria de los Municipios..., cuando estas entidades dicten sus correspondientes Ordenanzas Fiscales", por lo que "la norma municipal deberá señalar a los obligados al pago del tributo de forma abstracta e impersonal, deberá evitar también el establecimiento de beneficios fiscales que puedan reputarse como privilegios y, finalmente, deberá garantizar que no haya un trato discriminado a los sujetos pasivos del tributo que carezca de justificación". (F. HERNÁNDEZ GUIJARRO, "Los principios de generalidad e igualdad en la normativa tributaria municipal y su infracción por las ordenanzas fiscales", Revista boliviana de Derecho, 19, 2015, pág. 367). Asimismo, destacando la relevancia de respetar tales límites, véase $B$. MORENO SERRANO, "Haciendas locales. Bonificación en el IIVTNU por transmisiones mortis causa", La administración práctica: enciclopedia de administración municipal, 1, 2018.

41 Este es el caso, por ejemplo, de Segovia, donde se puntualiza que "se considerará vivienda habitual aquella en la que haya figurado empadronado el causante de forma ininterrumpida durante, al menos los dos años inmediatos anteriores al fallecimiento" (art. $2^{\circ} .2$ de la Ordenanza fiscal núm. 1.3 reguladora del Impuesto sobre el Incremento de Valor de los Terrenos de Naturaleza Urbana, aprobada por el Pleno de la Corporación de Segovia el 22 de octubre de 1998 (modificada por última vez por acuerdo de fecha 2 de diciembre de 2016). 
resulta plenamente aceptado que "los datos del empadronamiento suponen una presunción iuris tantum que puede desvirtuarse mediante prueba en contrario (art. 385 LEC y 108 LGT)", aunque ello no impide, lógicamente, que puedan utilizarse como presunción al respecto.

No obstante, conviene destacar también que muchos municipios han previsto de forma expresa el supuesto de que el causante o incluso el adquirente se encuentren habitando en una residencia geriátrica en el momento de la transmisión, como es el caso de Barcelona ${ }^{42}$, de $\mathrm{L}^{\prime}$ Hospitalet de Llobregat ${ }^{43} \mathrm{o}$, estableciendo un límite temporal al respecto, de Segovia ${ }^{44}$.

$Y$ es que, con carácter general, parece que, si no se hubiera contemplado ninguna precisión respecto, el inmueble que hubiera constituido la vivienda habitual del causante hasta su internamiento en un centro geriátrico habrá perdido tal carácter, no procediendo, en consecuencia, el derecho a la bonificación.

De todos modos, a la hora de otorgar la condición de vivienda habitual, procede destacar la conveniencia de que, con el fin de evitar situaciones discriminatorias, no se tengan en cuenta ni los traslados temporales (como pueden ser de trabajo o estudios) ni los de carácter forzoso (especialmente por motivos de salud, ya sea comportando el ingreso del causante en una residencia geriátrica o el traslado a la vivienda de un tercero de la que no fuera titular para que éste se haga cargo de su cuidado), por cuanto pueden darse diferencias de trato entre situaciones objetivamente comparables realmente difíciles de justificar.

A modo de ejemplo, este sería el caso donde, no siendo necesaria la convivencia entre el causante y el adquirente, se dejara fuera de la

42 Al respecto, tras reconocer una única bonificación del $95 \%$, el art. 90 de la Ordenanza fiscal núm. 1.3 reguladora del Impuesto sobre el Incremento de Valor de los Terrenos de Naturaleza Urbana (aprobada definitivamente por el Plenario del Consejo Municipal de Barcelona en fecha 29 de diciembre de 2015) contempla expresamente el supuesto de que el causante, en el momento del devengo del Impuesto, tuviera la residencia efectiva en otro domicilio del que no era titular, caso en el que concede la consideración de vivienda habitual al inmueble que la tenía hasta cualquier día de los diez años anteriores a su muerte (siempre que el uso de la vivienda no hubiera sido cedido a terceros mediante contraprestación en el periodo mencionado, o si se hubiera cedido, fuera mediante el pago de un alquiler social a través de la bolsa de vivienda de alquiler de Barcelona).

${ }^{43}$ En este punto, y aunque haciendo referencia de forma improcedente al contenido del empadronamiento, señala el art. 5 de la Ordenanza Fiscal 1.03 reguladora del Impuesto sobre el Incremento de Valor de los Terrenos de Naturaleza Urbana (modificada por acuerdo de Pleno de L'Hospitalet de Llobregat, en sesión de 22 de diciembre de 2015) que "no se perderá el derecho a la bonificación en el supuesto de que la falta de empadronamiento de la persona causante $\mathrm{y} / \mathrm{o}$ de su cónyuge en la vivienda habitual sea debida al empadronamiento en un centro sanitario o geriátrico, o haya estado motivada por causas de salud suficientemente acreditadas".

${ }^{44}$ En concreto, se señala en este caso "en el supuesto de que el causante hubiera cambiado de residencia dentro de los dos años señalados habiendo concurrido circunstancias que necesariamente exijan el cambio de domicilio, tales como (...) ingreso en residencia geriátrica" (art. 20.2 de la Ordenanza fiscal núm. 1.3 reguladora del Impuesto sobre el Incremento de Valor de los Terrenos de Naturaleza Urbana, aprobada por el Pleno de la Corporación de Segovia el 22 de octubre de 1998 (modificada por última vez por acuerdo de fecha 2 de diciembre de 2016). 
bonificación a un hijo que hubiera cuidado al causante en su propia casa, pero se reconociera a otro que, no habiendo habitando tampoco en la vivienda objeto de adquisición, nunca se hubiera hecho cargo del mismo.

$Y$ es que, sin ir más lejos, no se podrían alegar los fines constitucionalmente legítimos que tradicionalmente han justificado la procedencia de dicha bonificación ${ }^{45}$, en tanto que, al no constituir la vivienda habitual de ninguno de los adquirentes, no podría alegarse el derecho a disfrutar de una vivienda digna y adecuada del art. $47 \mathrm{CE}$, ni mucho menos, en tanto que los dos serían descendientes de primer grado, el deber de protección social, económica y jurídica de la familia del art. 39 de la CE.

\section{CONCLUSIONES}

A la hora de determinar la residencia habitual a efectos del ISD, deberá tenerse en cuenta la estancia del causante o de los contribuyentes en una residencia geriátrica (por ser el lugar donde permanecen y residen de forma efectiva), ya sea para determinar la sujeción al Impuesto, para valorar la aplicación de la bonificación en la cuota por la residencia en Ceuta o Melilla o a la hora de establecer su cesión.

No obstante, en este último supuesto, sería más que adecuado unificar el plazo de 5 años a la hora de fijar los puntos de conexión, ya sea para evitar cambios de residencia fraudulentos, para simplificar la gestión del impuesto $y$, en cualquier caso, para conseguir un mayor respeto al principio de igualdad (sin perjuicio de la necesidad de su reformulación para un íntegro cumplimiento del Derecho de la UE).

Por su parte, respecto a la reducción de la base imponible por la transmisión de la vivienda habitual del causante, su procedencia dependerá de la normativa que resulte de aplicación, no siendo así si se aplica la normativa foral o la estatal (por cuanto, a pesar de la posición del TS avalando su procedencia respecto a esta última cuando el transmitente no residiera en la correspondiente vivienda por motivos de salud -plasmada en la STS 841/2017, de 12 de mayo, en unificación de doctrina-, no parecen desprenderse tales consideraciones del tenor literal de la LISD y, por remisión, del RIRPF). Asimismo, tampoco operará si resulta de aplicación la normativa de las CCAA de régimen común, excepto en los casos de Canarias, Galicia y Cataluña (ya que en tales casos sí que se contempla su procedencia de forma expresa).

Sin embargo, considerando que la finalidad de dicha reducción se basa tanto en el derecho a disfrutar de una vivienda digna y adecuada (art. 47

\footnotetext{
${ }^{45}$ En este punto, procede recordar que su introducción vino a responder a las propuestas que el Informe de la Comisión para el estudio y propuesta de medidas para la reforma de la financiación de las haciendas locales, de 3 de julio de 2002, había señalado al respecto, el cual, tras señalar que en el IIVTNU "se echa en falta la existencia de alguna exención en las transmisiones hereditarias realizadas a favor del cónyuge y los hijos", añadió que "al menos debe pensarse en la posibilidad de introducir bonificaciones o exenciones que afecten a la transmisión hereditaria de la vivienda familiar" (Informe de la Comisión para el estudio y propuesta de medidas para la reforma de la financiación de las haciendas locales, de 3 de julio de 2002, Ministerio de Hacienda, Madrid, 2002, pág. 125).
} 
de la CE) como en la protección social, económica y jurídica de la familia (art. 39 de la CE), cierto es que la falta de residencia del causante en la vivienda transmitida a causa de su ingreso en un centro geriátrico no parece motivo suficiente para dejar de garantizar ambos objetivos (especialmente en aquellos casos donde los adquirentes vivan de forma efectiva en el inmueble que van a recibir y deban hacer frente a la pertinente tributación), sin olvidar la posible confrontación con los principios de igualdad y generalidad tributarios que supone el hecho de que ascendientes, descendientes y cónyuges que vivieran separados del causante e incluso tuvieran una vivienda habitual propia (puesto que, respecto a los mismos, no se les exige el requisito de convivencia) sí que podrán tener derecho a la misma (pudiendo aplicarla tantas veces como viviendas habituales reciban).

Por consiguiente, mientras se siga previendo la mencionada reducción, sería deseable una modificación de la LISD contemplando expresamente los casos aquí estudiados, lo que, además de un mayor respeto a los principios tributarios, permitiría ajustar a la normativa la posición que al respecto mantiene el TS.

Y por lo que respecta al ajuar doméstico, no se desvirtuará su existencia por el mero hecho de probar, sin más, que el causante residía en una residencia geriátrica, sino que también deberá acreditarse, a pesar de la dificultad que ello puede conllevar, que carecía de bienes muebles, ropas o enseres propios tanto en la propia residencia como fuera de la misma. De este modo, si no se prueba de forma fehaciente, deberá incluirse en la base imponible de cada causahabiente conforme a las reglas de presunción de su valor que prevén la LISD y el RISD, siendo adicionado de oficio si no se hubiera incluido en el inventario de los bienes relictos del causante por la propia Administración.

Finalmente, respecto a la bonificación de la cuota íntegra del IIVTNU, establecida por algunos Ayuntamientos, en las transmisiones por causa de muerte de la vivienda habitual del causante, y la transmisión o constitución de derechos reales de goce limitativos del dominio sobre la misma, deberá atenderse a la concreta regulación aprobada en cada municipio, aunque, si no se contempla ninguna precisión respecto al hecho de que el causante estuviera habitando de forma efectiva una residencia geriátrica o un centro similar, parece que el inmueble que hubiera constituido su vivienda habitual hasta su internamiento habrá perdido tal carácter y no procederá el derecho a su aplicación.

No obstante, para el pleno respeto a los principios de justicia tributaria y con el fin de evitar supuestos injustificados de discriminación, sería deseable que, en aquellos casos donde se encontrara prevista la mencionada bonificación, no se tuvieran en cuenta ni los traslados temporales ni los de carácter forzoso (como sería el ingreso a una residencia geriátrica por motivos de salud), sin olvidar la necesidad de reformulación de todas aquellas disposiciones que vinculen su procedencia al contenido del padrón municipal.

\section{BIBLIOGRAFÍA}


P. ÁLVAREZ BARBEITO, "Doctrina administrativa y jurisdicional sobre la reducción por adquisición mortis causa de la vivienda habitual del causante", Estudios financieros. Revista de contabilidad y tributación: Comentarios, casos prácticos, 329-330, 2010.

J. CALVO VÉRGEZ, "La reducción por adquisición mortis causa de la vivienda habitual del causante en el Impuesto sobre Sucesiones: análisis de las principales cuestiones suscitadas a la luz de la reciente doctrina administrativa", Quincena Fiscal, 18, 2008.

J. CALVO VÉRGEZ, "¿Se adapta la reforma de los puntos de conexión del ISD acometida a través de la aprobación de la Ley 26/2014, de 27 de noviembre, a los dictados de la Sentencia del TJUE de 3 de septiembre de 2014?", en Derecho y fiscalidad de las sucesiones "mortis causa" en España: una perspectiva multidisciplinar, Aranzadi, Cizur Menor, 2016.

V. CARO ROBLES, "La transmisión de la empresa familiar y de la vivienda habitual en el Impuesto sobre Sucesiones y Donaciones", Revista de Contabilidad y Tributación, 223, 2001.

F. ESCRIBANO LÓPEZ, "Libertad de establecimiento y libre circulación de capitales: la proscripción de diferencias de tratamiento tributario por razón de residencia dentro de la UE de sujetos y objetos en el ISD español", en Derechos fundamentales y Hacienda Pública: una perspectiva europea, Cívitas, Madrid, 2015.

R. FALCÓN Y TELLA, "Las reducciones en la base imponible del Impuesto sobre Sucesiones y Donaciones en materia de vivienda habitual y empresa familiar: el discutible criterio de la Dirección General de Tributos", Quincena Fiscal, 8, 1999.

R. FALCÓN Y TELLA, "El impuesto sobre sucesiones y donaciones y la libre circulación de capitales: una enmienda insuficiente", Quincena fiscal, 18, 2014.

J.F. GARCÍA DE PABLOS, "El Impuesto sobre Sucesiones y Donaciones: supresión o reforma", Crónica Tributaria, 139, 2001.

J.F. GARCÍA DE PABLOS, El Impuesto sobre Sucesiones y Donaciones en España, Aranzadi, Cizur Menor, 2010.

F. HERNÁNDEZ GUIJARRO, "Los principios de generalidad e igualdad en la normativa tributaria municipal y su infracción por las ordenanzas fiscales", Revista boliviana de Derecho, 19, 2015.

P.M. HERRERA MOLINA, Capacidad Económica y Sistema Fiscal. Análisis del ordenamiento español a la luz del Derecho alemán, Marcial Pons, Madrid, 1998.

M. INDA ERREA, "Valoración del ajuar doméstico en el Impuesto de Sucesiones y Donaciones: Consulta vinculante núm. V0832-17, de la DGT, de 4 abril 2017", Revista Aranzadi Doctrinal, 7, 2017.

J. MARTÍN QUERALT, "El Impuesto sobre Sucesiones y Donaciones: de la vulneración del Derecho comunitario a la mera inconstitucionalidad", Tribuna Fiscal, 275, 2014.

B. MORENO SERRANO, "Haciendas locales. Bonificación en el IIVTNU por transmisiones mortis causa", La administración práctica: enciclopedia de administración municipal, 1, 2018. 
J.L. MUÑOZ DEL CASTILLO, "El ajuar doméstico en el Impuesto sobre Sucesiones", en Estudios de derecho financiero y tributario en homenaje al profesor Calvo Ortega, Vol. 2, Lex Nova, Madrid, 2005.

J.L. PEÑA ALONSO, "El ajuar doméstico en el impuesto sobre sucesiones, en Homenaje al profesor Carlos Vattier Fuenzalida, Thomson ReutersAranzadi, Madrid, 2013.

A.M. PITA GRANDAL, La prueba en el procedimiento de gestión tributaria, Marcial Pons, Madrid, 1998.

F. QUESADA SANTIUSTE, Impuesto sobre el Incremento de Valor de los Terrenos de Naturaleza Urbana, Bayer Hermanos, Barcelona, 2001.

J. RAMOS PRIETO, "La tributación de las sucesiones mortis causa en España: una visión general desde la perspectiva del Derecho interno y del Derecho de la Unión Europea", en Derecho y fiscalidad de las sucesiones "mortis causa" en España: una perspectiva multidisciplinar, Aranzadi, Cizur Menor, 2016.

J.A. ROZAS VALDÉS, "La vivienda en el Impuesto sobre sucesiones y donaciones", en La fiscalidad de vivienda en España, Civitas-Thomson Reuters, Madrid, 2012.

E. SIMÓN ACOSTA, "Incompatibilidad del Impuesto sobre Sucesiones y Donaciones con el ordenamiento comunitario", Actualidad Jurídica Aranzadi, 891, 2014.

J.M. TOVILLAS MORÁN, "El Régimen jurídico del ajuar doméstico en la reciente jurisprudencia", Revista Fiscal \& Laboral al Día, 162, 2008. 